\title{
MECHANICAL PROPERTIES OF POLYPROPYLENE FIBERS MIXED CEMENT-SAND MORTAR
}

\author{
Bilal Zaman Afridi ${ }^{1}$, Khan Shahzada ${ }^{1}$, Muhammad Tayyab Naqash ${ }^{2}$ \\ ${ }^{1}$ University of Engineering \& Technology, Peshawar, Pakistan \\ ${ }^{2}$ Faculty of Engineering Islamic University Madina, Kingdom of Saudi Arabia
}

The polypropylene fibers are mostly used in concrete nevertheless much focus is not made on its use in mortar. Therefore, this research was carried out to determine the beneficial use of polypropylene fibers in cement-sand mortar. By determining the mechanical properties of polypropylene fibers Mixed (PPFM) Cement-Sand Mortar we can assess it beneficial use. The PPFM Cement-Sand Mortar (Type- $N$ ) contains Polypropylene Fibers randomly mixed in cement-sand mortar. This idea is based on the previous research carried out on Polypropylene Fibers Reinforced Concrete. The fibers used were microfilament fibers having length of $12 \mathrm{~mm}$, diameter of 18 micron and specific gravity of 0.91 . The fibers were mixed in mortar in different proportions (1\%, $2 \%$ and $3 \%$ by the volume fraction) in cement-sand mortar of 1:6 (by volume fraction) and its mechanical properties were studied with control samples (Mortar with no fibers). A total of 08 tests were performed: 4 tests were performed in fresh state of mortar, 4 were performed in hardened state of mortar. In fresh state, 12 samples for each test were casted and the mortar showed considerable decrease in workability, bulk density and setting time whereas the air content increased considerably with increasing PPF fraction. In hardened state, 48 samples were casted for each test and the mortar samples showed considerable decrease in compressive strength, tensile strength and flexural strength with increasing PPF fraction, however, the ductility increased considerably. Based on the results, it was concluded that the use of polypropylene fibers does increase the ductility of the mortar, however, the strength does decrease, and therefore, its use may be limited to less that $1 \%$ so that ductility is achieved, and strength of mortar is not affected much. In view of above, this work can be extended for calculating its optimum use in cement sand mortar.

Key words: Polypropylene Fiber, Workability, Setting Time, Porosity, Strength, Permeability

\section{INTRODUCTION}

In Pakistan, mortar is generally classified into two types; plastering mortar and masonry mortar. The plastering mortar contains sand with higher fineness modulus for smoother surface while the masonry mortar contains sand with lesser fineness modulus. The use of mortar is inevitable in construction industry, especially in brick/ block masonry if seen from the angle of aesthetic appearance as well as structural consideration. Like concrete, the ductility of mortar is also limited with little resistance to cracking and low tensile strength. Mortar may be subjected to tension due to dynamic loading during seismic events, temperature changes (freeze and thaw) and shrinkage, when the tensile strength of mortar is surpassed by such type of external loading, cracking occurs which not only affects the aesthetic appearance of the building but also damages the structure by making it permeable. If the crack width is controlled within a certain limit, it may increase the serviceable life of a structure. Many researchers focus on the use of polypropylene fibers in concrete.

Johnston[1] concluded that the inclusion of coarse aggregates in fiber reinforced concrete typically decreases the fiber content of the material and consequently the reinforcement effectiveness of the fibers, therefore, the mortars are more effective than concretes with fibers addition.
Okan Karahan and Cengiz Duran Atis [2] found that the use of polypropylene fibers in concrete decrease the workability, compressive strength and elastic modulus of concrete when compared with the Portland cement concrete or fly ash concrete. However, it does increase the freezing and thawing resistance of concrete.

A research work regarding the properties of polypropylene fibers reinforced concrete carried out by Ahmed\& Siddiqui [3] at the University of Engineering and Technology, Taxila concluded that the compressive strength of concrete increases at low values of polypropylene fibers but at higher values the compressive strength decreases by $3 \%$ to $5 \%$ from that of ordinary concrete. With polypropylene fibers up to $0.4 \%$, the tensile strength increases and reaches a maximum value of $70 \%$ more than that of ordinary concrete samples, after that value the strength decreases. At $0.2 \%$ polypropylene fibers, the flexural strength reaches a maximum value of $80 \%$ more than that of the control sample, afterwards it decreases. In the range of $0.35 \%$ to $0.5 \%$, the polypropylene fibers induce shrinkage crack resistance in the concrete and are increased up to $85 \%$ more than that of the ordinary concrete sample.

Islam \& Gupta[4] observed that with the addition of polypropylene fibers in a fraction range of $0.1 \%$ to $0.3 \%$, it was observed in the experimental study that the plastic shrinkage cracks reduced by $50 \%$ to $99 \%$. 
However, with addition of fibers it was observed that the permeability coefficient for both water and gas increased. Therefore, the use of fiber reinforced concrete may be limited to plastic shrinkage susceptible elements and its use for water retaining structures must be considered carefully.

Alhozamy \& Soroushian [5] writes in their research work that the addition of polypropylene fibers showed no significant effects on the compressive and flexural strength of concrete. However, the flexural toughness and impact resistance increased considerably.

About ductility of mortar in compression Fanella \& Naaman [6] writes that the addition of steel, glass, monofilament polypropylene and twisted polypropylene fibers to mortar in various volume fractions confined the material and delayed crack propagation, thus increasing the peak strain and post peak ductility.

During the experimental study of the properties polypropylene fiber reinforced concrete as well as steel fiber reinforced concrete Li Xing \& Cheng Xian [7], it was observed that with addition of low volume of polypropylene fibers slightly decreased the compressive and shear strengths and increased the flexural strength besides enhancing the toughness index and fracture energy of concrete. The polypropylene as well as the steel Fibers has no great beneficial effect on the abrasion-erosion resistance of concrete.

For determining the strength properties of polypropylene fiber reinforced concrete, experimental investigations were carried out by Kolli Ramujee [8], he drew conclusions that the slump was noted to be decreasing with increasing fiber, beyond $1.5 \%$ fraction of the fiber, the concrete become difficult to handle. The compressive and split tensile strengths of the fiber reinforced concrete increased proportionately with increase fiber content on comparison to control mixes. The maximum recorded increase in compressive and split tensile strength was $34 \%$ and $40 \%$ compared to the control mixes without fibers. The optimum results were obtained at fiber content of $1.5 \%$, below and above this fraction the results decreased.

Aulia [9] writes that during fire, the temperature of the structure rises, heat penetrates into the structure, due to which desorption of moisture occurs in the outer layer of the structure. Some of the moisture vapors flow back towards the cold interior and are reabsorbed. The water vapors that accumulate in the interior increase the pressure causing cracks and spalling in the mortar. In case of PFRC, the fibers melt at $1600 \mathrm{C}$ creating voids. The vapor pressure is released in newly formed voids and explosive spalling is significantly reduced.

Deng and Li [10] writes that in structures, cracks play an important role as they change them from impermeable elements to permeable elements; consequently, risk of corrosion arises. Besides, cracks reduce the quality of the structure, make it aesthetically unacceptable and in some cases also make it out of service. If the cracks are confined to certain widths, they are neither harmful to structures nor to its serviceability. Therefore, it is important to reduce the crack width, and this can be achieved by adding polypropylene fibers.

Ramlal and Selokar [11] writes that in concrete matrix bridges, the additions of fibers restrain the cracks from opening. This process, apart from preserving the integrity of the structure, improves the load-carrying capacity of the structural member beyond cracking.

Some of the conclusions of a research work carried out by Shehnila Fatima [12] are that with low volume fractions of polypropylene fibers, early age shrinkage and moisture loss of the concrete mix is reduced. Deformation capacity and ductility of concrete in compression is increased with addition of polypropylene fibers. The mode of failure of polypropylene fibers reinforced concrete is different from that of plain concrete. In compression, the Fibers in concrete arrest the cracks and smudge it over a larger area. The addition of polypropylene fibers increases the post peak deformation capacity by bridging the cracks that appear in the concrete after it reaches its tensile strength. The plain concrete beams exhibit a very brittle behavior when subjected to flexural loading whereas the polypropylene fiber reinforced concrete beams show ductile failure.

The research work carried out by Ece Erdogmous [13], concluded with recommendations that composition and strength of the initial cementations matrix as shown in both the masonry and the concrete structure application studies, the lower strength matrices may benefit more from the fiber addition compared to stronger base matrices. Flexural strength, toughness, energy absorption, and ductility of the FRM themselves are typically higher compared to the control mixture, even with lower fiber percentages. Bond strength with units in flexure and shear also seem to be positively affected from the addition of fibers, depending upon the target flow rate (water content) and type of unit.

\section{ADOPTED MATERIALS}

The Cement used in this study was Ordinary Portland conforming ASTM C-150 (Type-I) Grade 43[5]. The initial and final setting time of cement was 30 minutes and 330 minutes respectively. Specific gravity of cement was 3.25. Sand was obtained was conforming to ASTM C-33 [6] having Fineness Modulus of 2.35. The specific gravity of sand was 2.65. Water used for mixing and curing was fresh, clean and free from amounts of oils, acids, organic materials and inorganic matters in solutions or in suspension. The specific gravity of water at $40 \mathrm{C}$ was 1 . First class bricks free from cracks and flaws with sharp pointed ends were used. The average size of the brick was $8.75 "$ x 4.25" x 2.75". The average weight of oven dried brick was $2.78 \mathrm{Kg}$ and the percent absorption was $13.35 \%$. The average compressive strength of the brick was 3909.1 psi. The average specific gravity of brick was 1.66 . 


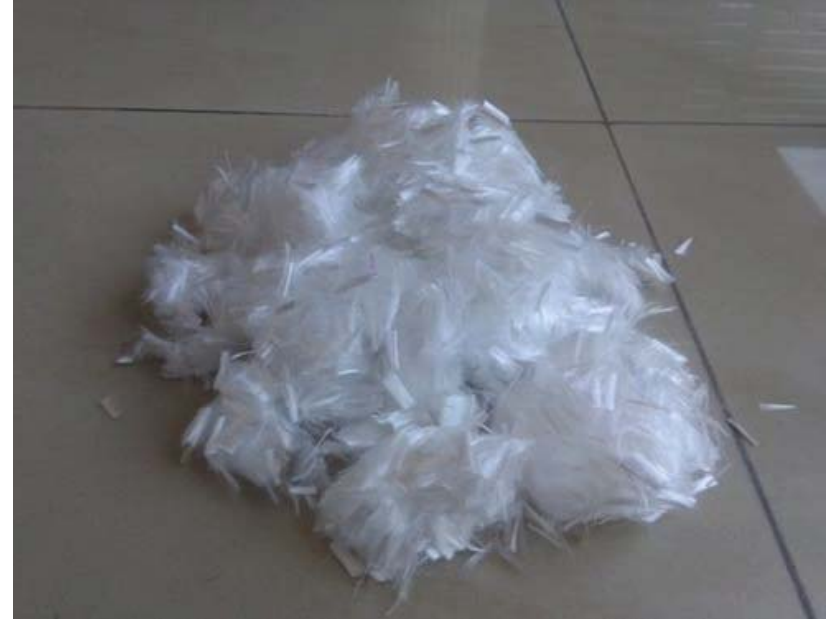

Figure 1: Polypropylene Fibers

The fibers used were microfilament fibers having length of $12 \mathrm{~mm}$, diameter of 18 micron and specific gravity of 0.91. The aspect ratio of the fibers was 666.67. The fibers were free of alkalis, sulphates and chlorides. The polypropylene fibers as shown in Figure 1 were acquired from renowned local firm.

\section{METHODOLOGY}

To determine the mechanical properties of the PPFM cement-sand mortar, the following tests on mortar (fresh and hardened state) were performed:

- Determination of Consistence of Fresh Mortars (By Flow Table)ASTM C-1437-15[7].

- Determination of Air Content of Fresh Mortar ASTM C-231/231M-14[8].

- Determination of Initial Setting Time of Fresh Mortar ASTM C-807-13[9].

- Determination of Compressive Strength of Hardened Mortar ASTM C-109/C109M-16A[10].

- Determination of Tensile Strength of Cement Mortar ASTM C-307-3 [11] .

- Determination Flexural Strength of Cement Mortar ASTM C-1609/ C1609M-12[12].

- Determination of the Permeability of Hardened Mortar German Standard [13].

\section{- CASTING}

The research was planned in such a way to clearly examine the effect of the inclusion of Microfilament Polypropylene Fiber. A mix design (1:6) was prepared for this purpose, mortar samples (with and without fibers) were made at water-cement ratio of 1.1 at varying quantities of fibers added to the mix. Polypropylene Fibers fraction used in this study are $1 \%, 2 \%$ and $3 \%$ by volume because my predecessors have used the same method of selecting the fibers quantity so in order to have consistency among the results volumetric study was carried out. The mixing of mortar was carried out in a mechanical mixer. The samples of fresh mortar were tested at the same time whereas those for hardened mortar were poured compacted in layers in moulds of required shape as per ASTM standards made of wood and tested at 3 days, 7 days, 14 days and 28 days (See Figure 2).

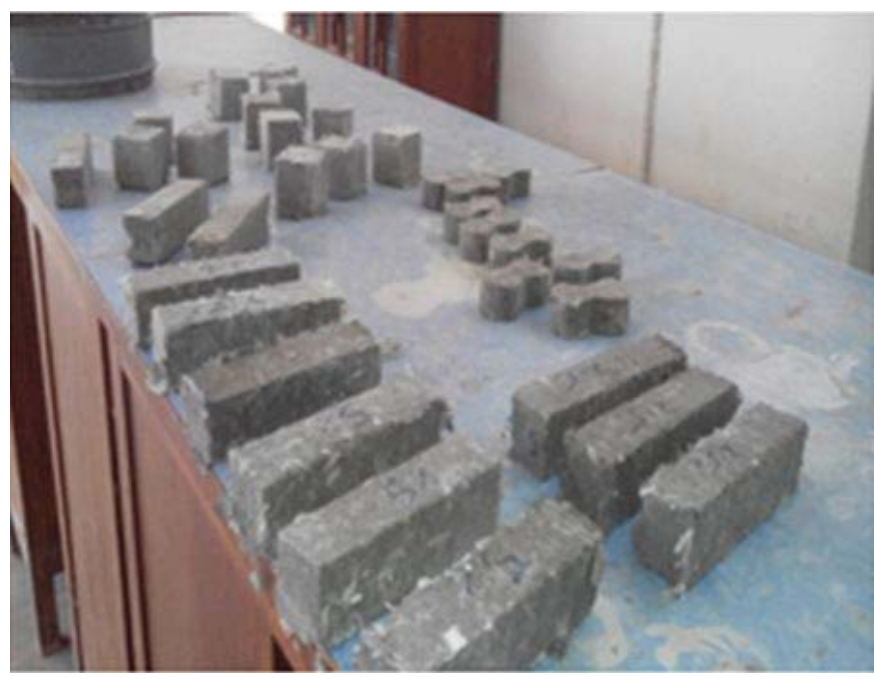

Figure 2: Hardened Samples

\section{Mixing}

The following mixing sequence was used for making mortar mix:

Firstly, the fine aggregate (dry) 6 times by volume of cement were poured. Then cement was added to sand and mixed until uniformity was achieved. Polypropylene $\mathrm{Fi}$ bers mixed in water (approximately $50 \%$ of total fraction) were poured. The fibers were uniform throughout the mix. More water was added in the end remaining 50\% of the total fraction and mixing was carried out in such a way to avoid wastage of water and to produce a uniform paste. The mortar was then poured into the lubricated moulds in layers by compacting it with the help of a tamping rod.

\section{Curing}

The mortar samples were kept in water filled tub after day 1 . The samples were removed few hours before their testing for making them sufficiently dry so that no water tippling occurs during testing but keeping the samples in moist condition. The strength period was counted from the setting time of mortar i.e. 3 days strength test was carried out after 72 hours + Initial Setting Time of Mortar and so on.

\section{Testing}

In this section tests such as Workability, Porosity, Setting Time, Compressive Strength, Tensile Strength, Flexural Strength and Permeability on the samples have been performed and the corresponding results are shown in figures and discussed accordingly. 


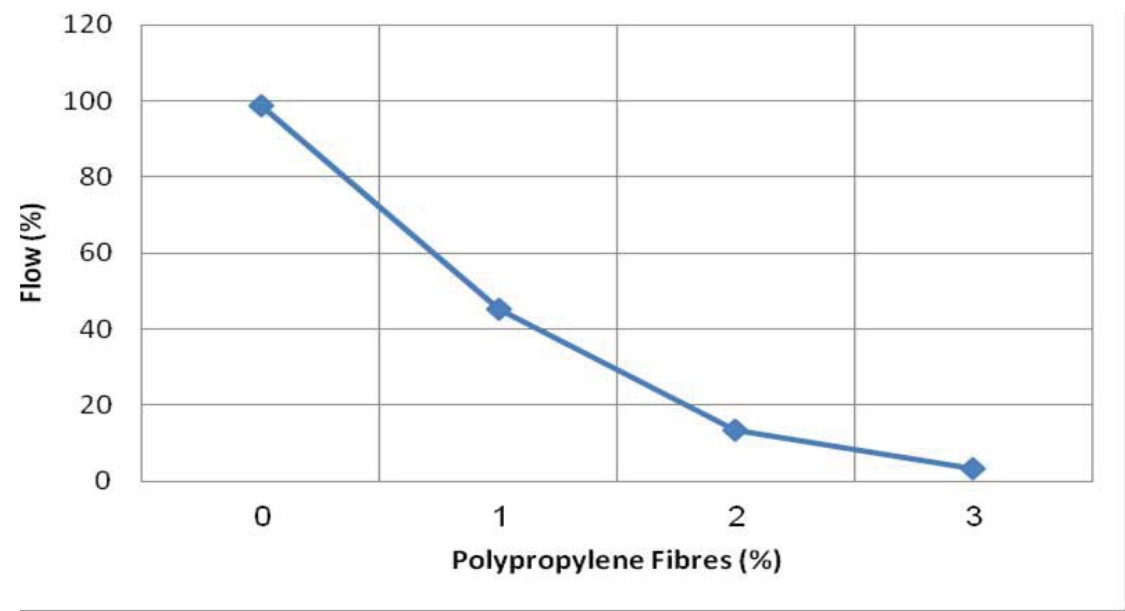

Figure 3: Graph showing Flow of PPF Mixed Mortar

WORKABILITY: The flow of hydraulic cement mortar was determined in order to establish the capability of mortar mix flow in Percentage (\%). The flow table was wiped out clean and dry. The mould was then placed in the center. The first layer of the mortar about 1 inch thick was laid in the flow mould and tamped 20 times with the tamper. The tamping was done uniformly. The same procedure was repeated for subsequent layers. After the top layer was tamped, the mortar was cut off to a plane surface and flushed it with the top of the mould with the help of a straightedge. After 1 minute the flow mould was lifted and then the table was immediately dropped 25 times in 15 seconds. With the help of caliper, the final diameter of the mortar mix was noted to determine the percent flow. It was observed (See Figure 3) that the workability of the PPFMM started to decrease with increase in the fraction of the PPF, this situation is like PPFRC i.e. with PPF $1 \%$ the workability decreases by $54.09 \%$, with PPF $2 \%$ the workability decreased by $86.49 \%$ and at $3 \%$ PPF the workability nearly vanished i.e. reduced by $96.62 \%$.

POROSITY: The air content of the hydraulic cement mortar was determined in Percentage (\%) using Air Meter as shown in Figure 4. The interior of the air meter was dampened. It was then placed on a firm level surface. The first layer of mortar (2 inches) was poured and tamped it uniformly 20 times with the help of tamper. The outside of the air meter was hit with the help of mallet about 10 times. The container was filled to the top in the same way for subsequent layers. After tamping the top layer, the mortar was cut off to a plane surface and flushed it with the top of the mould with the help of a straightedge. The edges of the container were wiped out clean. The top cover of the air meter was placed and clamped with the base ensuring a pressure tight seal. The main air value between the air chamber and the bowl was closed. Both the petcocks on the cover were opened. Water was poured with the help of rubber bulb syringe in one of the petcock until it emerged from the other end. The air bleed valve was closed, and the air was pumped in to the chamber until the dial gauge came on initial pressure line. Both the petcocks were then closed. The main air valve between air chamber and bowl was opened to give us the reading for percent air content on the dial gauge. The reading to the nearest $0.1 \%$ was noted on the dial gauge.

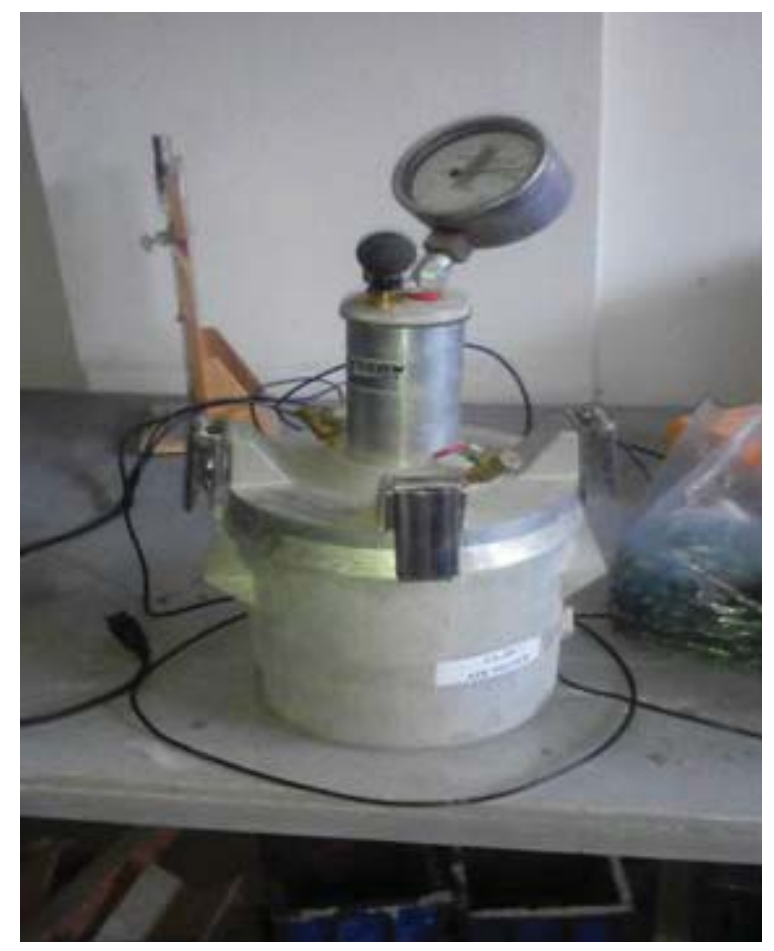

Figure 4: Air Meter

The air content of the PPFMM increased with increasing PPF's fraction the same situation is for PPFRC i.e. for PPF at $1 \%$ it increased $13.41 \%$, for PPF at $2 \%$ it increased $91.46 \%$ and for PPF 3\% it increased $110.96 \%$ (See Figure 5). 


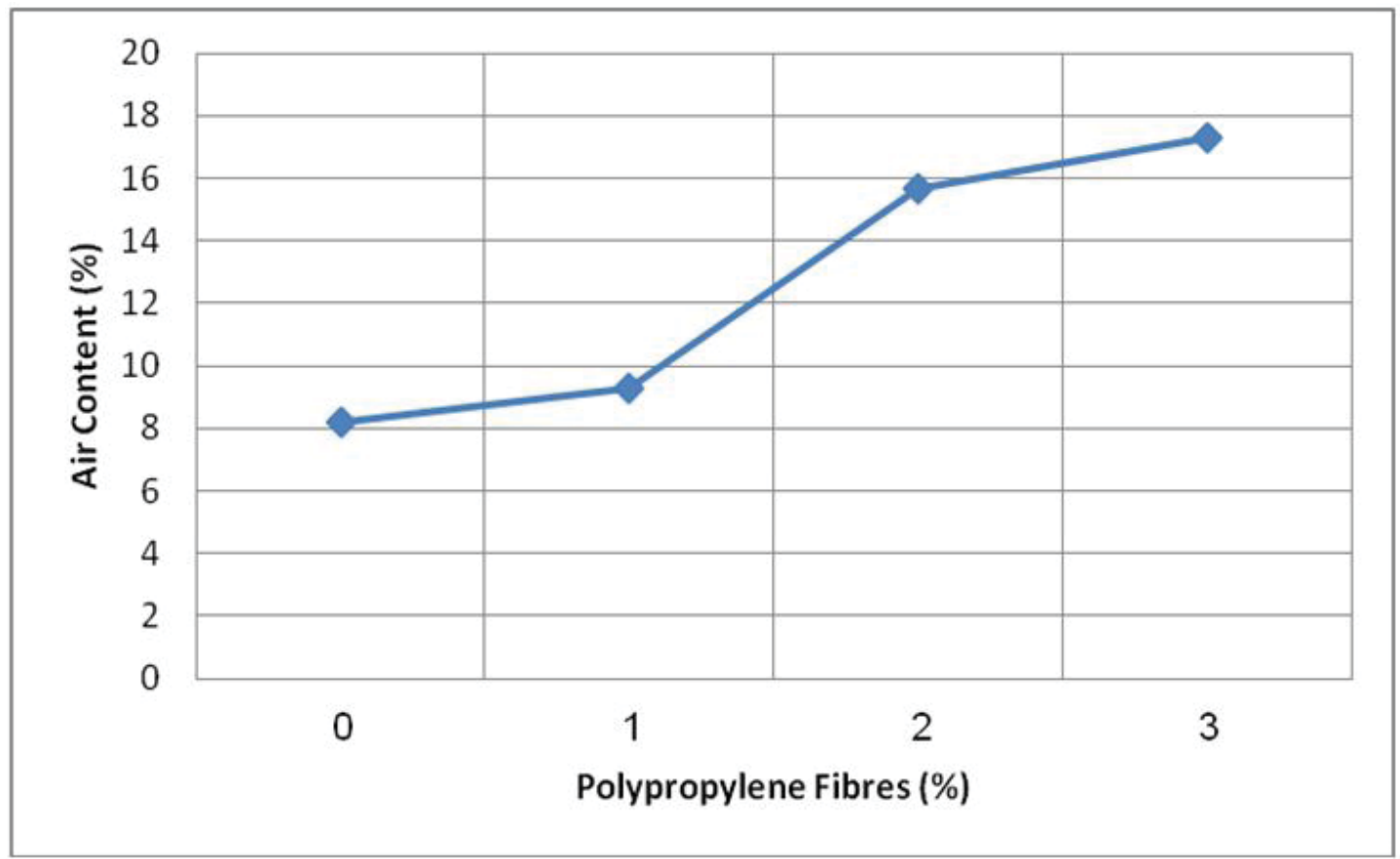

Figure 5: Graph showing increase in Air Content of PPF Mixed Mortar

SETTING TIME: The potential of mortar mix initial setting time in Minutes or Hours (min or hr) was determined by "Modified Vicat's Apparatus" as shown in Figure 6. The first layer of mortar about 1 inch thick was laid in the mould and tamped 20 times with the tamper. The tamping was done uniformly. The same procedure was repeated for subsequent layers. After the top layer was tamped, the mortar was cut off to a plane surface and flushed it with the top of the mould with the help of a straightedge. The mould was placed in a moist closet where it remained except when penetration tests were being made. After 30 minutes without being disturbed, the mould was taken out and the modified Vicat's needle was brought in contact with the surface of the mortar and tightened the setscrew. The initial reading was taken. The rod was released quickly by releasing the setscrew and allowed the needle to settle for 30 seconds. The penetration of this needle at this time was determined and every 30 minutes after until the needle failed to penetrate the bottom of the mould. Then, the penetration tests were carried out every 10 minutes until a penetration of $10 \mathrm{~mm}$ or less was obtained. The results of all penetration tests were noted down. With the help of interpolation, the time taken by the needle to penetrate exactly $10 \mathrm{~mm}$ was determined. The initial setting time of mortar was the difference of minutes between the time of contact between water and cement and the time taken to get $10 \mathrm{~mm}$ penetration.

The initial setting time of the PPFMM decrease with increase in PPF's fraction as in PPFRC. As evidence from Figure 7, at room temperature of 15 degrees Celsius, for PPF at $1 \%$ it decreased by $35.71 \%$, for PPF at $2 \%$ it decreased by $64.28 \%$ whereas for PPF at $3 \%$ it decreased by $85.71 \%$.

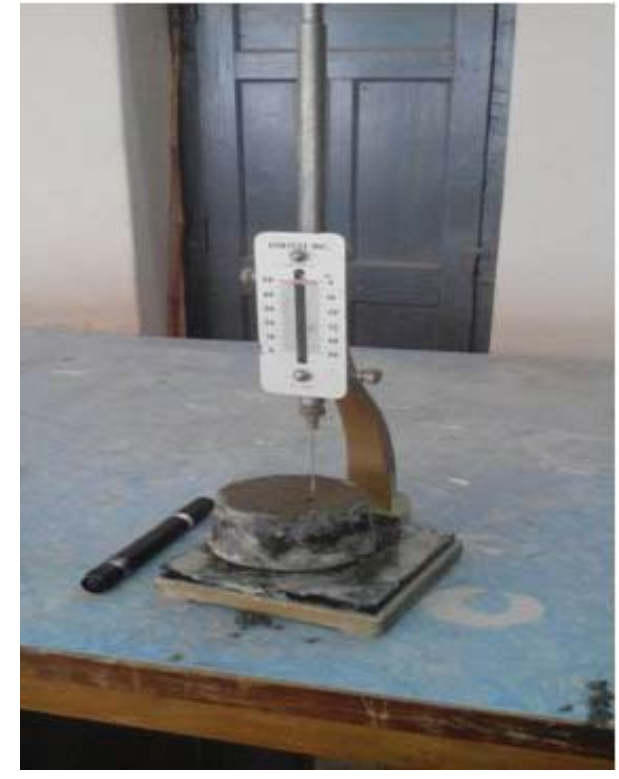

Figure 6: Vicat's Apparatus

COMPRESSIVE STRENGTH: The compressive strength of hydraulic cement mortar (See Figure 8) was determined in pounds/inches2using UTM as shown in Figure 8. For gaining the oriented results, standard cubes of 2" $\times 2$ " $\times 2$ " were made using the procedure illustrated in the ASTM standard. Forty-eight wooden moulds were prepared for making 48 samples to be tested. The interior faces of the moulds were first lubricated with oil and the excess oil was then wiped off with the help of the cloth. The halves of the moulds were sealed with grease. Then the first layer of mortar was poured in 1 inch thickness in the mould and tamped 20 times with the tamper. The tamping was done uniformly. 


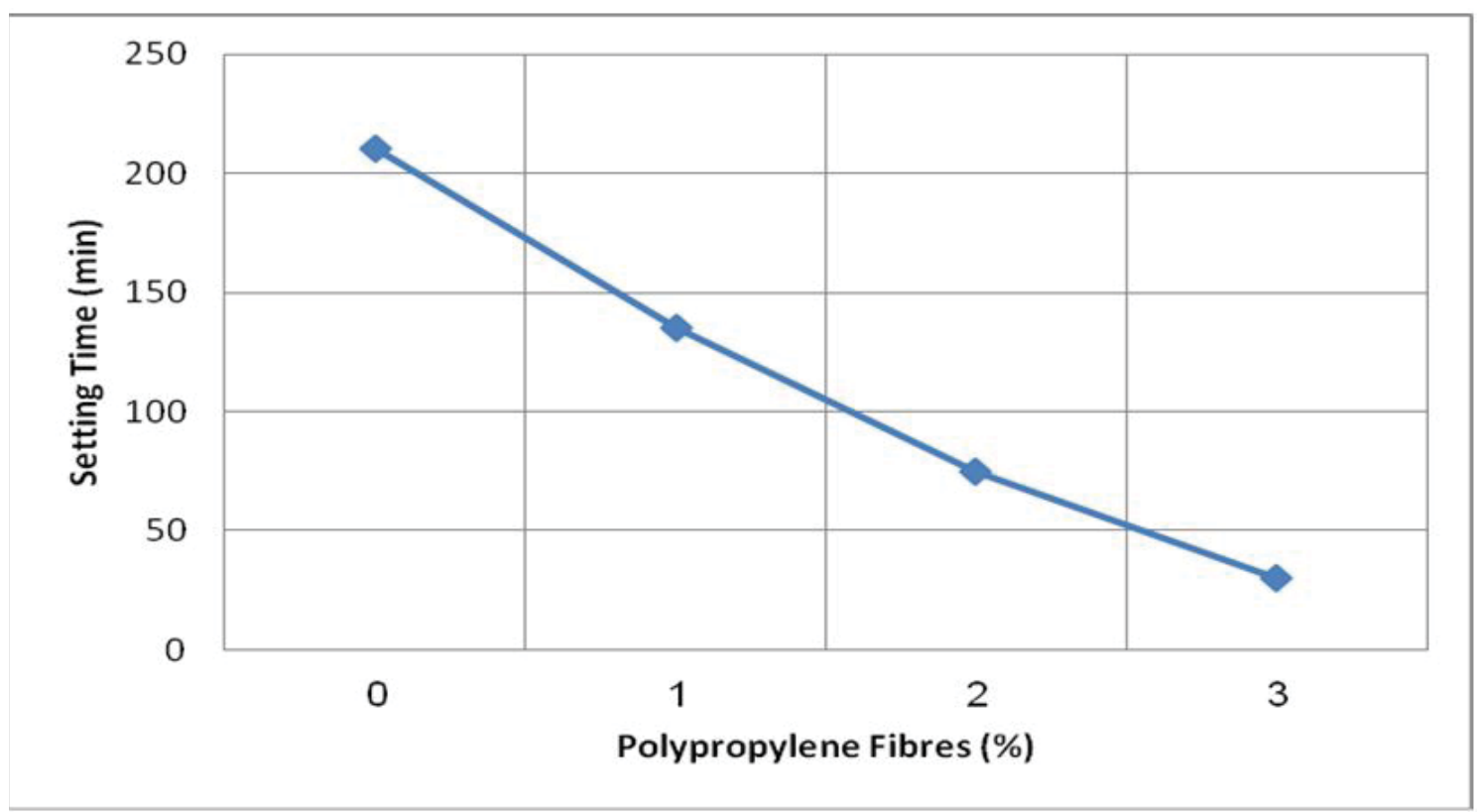

Figure 7: Graph showing decrease in initial setting time with increasing PPF Mixed Mortar
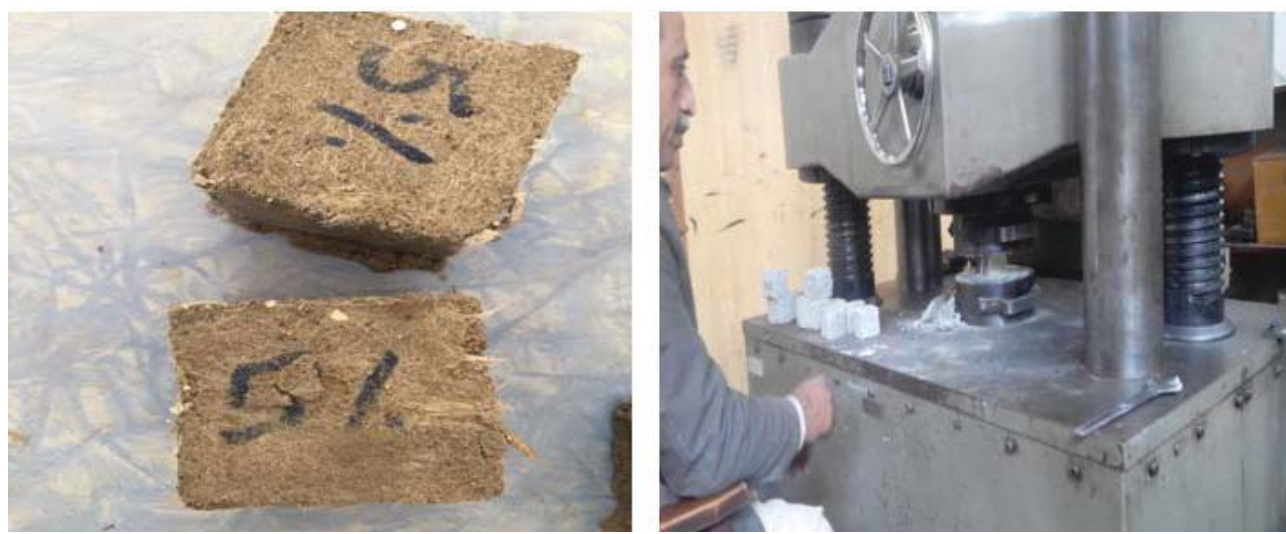

Figure 8: Cube Samples (Left) \& Universal Testing Machine (Right)

The same procedure was repeated for second layer. After the top layer was tamped, the mortar was cut off to a plane surface and flushed it with the top of the mould with the help of a straightedge. In this way all the forty-eight moulds were filled with specified mixes. The moulds were kept in a moist room for 24 hours. The mortar cubes were then taken out of the moulds by loosening the screws fixed in the wooden moulds.

The mortar cubes were then kept in water filled pan in such a way that their top faces do not drip into water. The hardened samples were then tested in the Universal Testing Machine to give crushing load. Considering the 28 days mortar cube compressive strength, it is observed (See Figure 9) that for PPF at 1\% the reduction in the compressive strength is $2.59 \%$, for PPF at $2 \%$ is $17.96 \%$ and for PPF at $3 \%$ is $20.24 \%$.

TENSILE STRENGTH: The tensile strength of hydraulic cement mortar was determined with the help of "Briquette Apparatus" as shown in Figure 10 to establish the capa- bility of mortar mix under the tensile loadings in pounds/ inches2. Forty-eight wooden moulds were prepared for making 48 samples to be tested. The interior faces of the moulds were first lubricated with oil and the excess oil was then wiped off with the help of the cloth. The halves of the moulds were sealed with grease. The mortar was poured in single in the mould and tamped 20 times with the tamper. The tamping was done uniformly. The mortar was cut off to a plane surface and flushed it with the top of the mould with the help of a straightedge. In this way all the forty-eight moulds were filled with specified mixes. The moulds were kept in a moist room for 24 hours. The mortar briquettes were then taken out of the moulds by loosening the screws fixed in the wooden moulds. The mortar briquettes were then kept in water filled pan in such a way that their top faces do not drip into water. The hardened samples were then tested in the Briquette Testing Machine to give the tensile load at failure. 


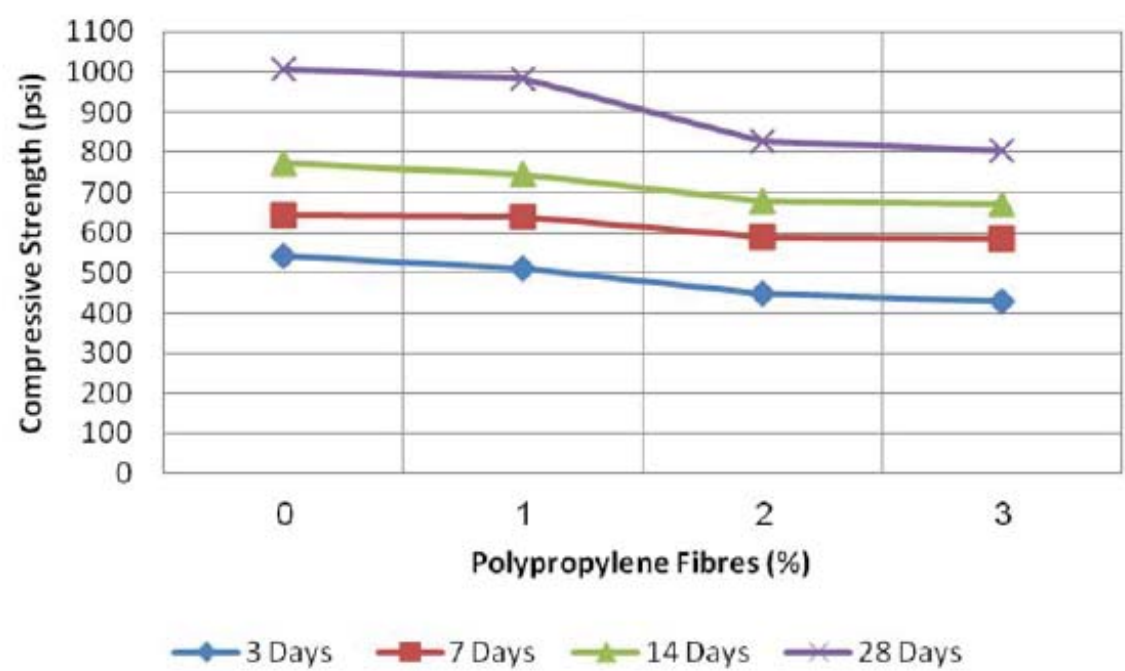

Figure 9: Graph showing decrease in compressive strength with increasing PPF
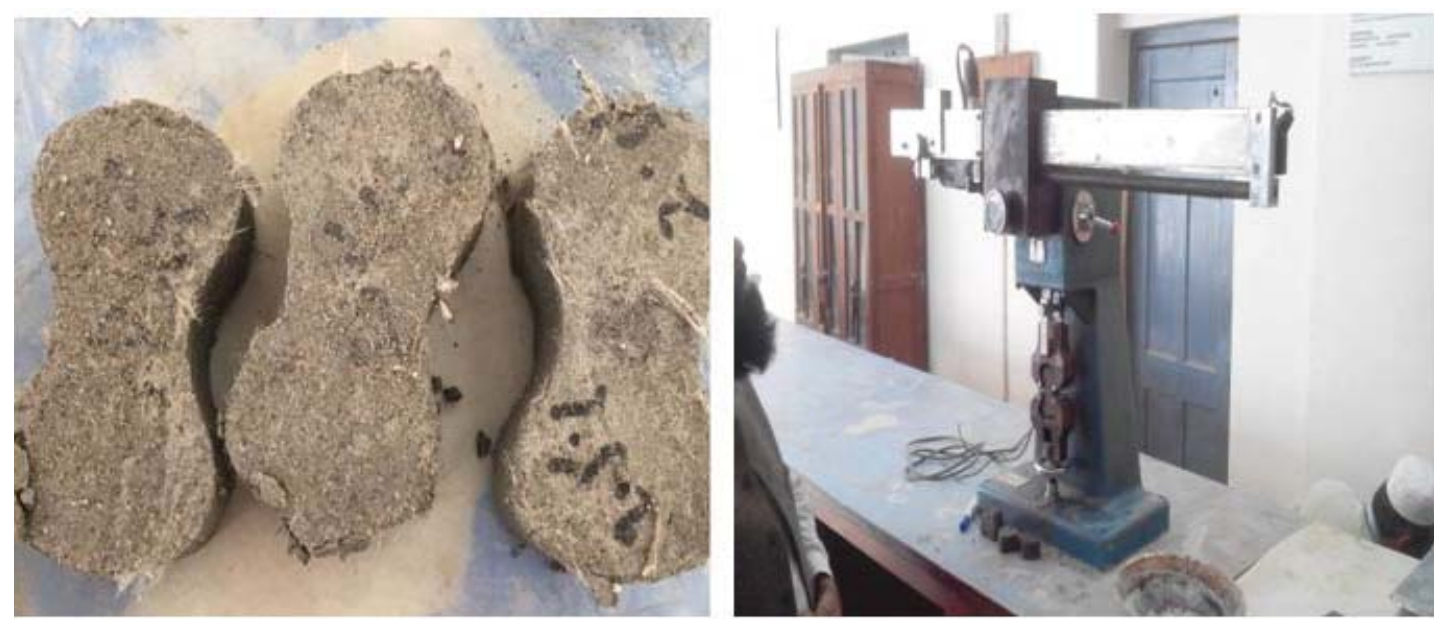

Figure 10: Briquette Samples (left) \& Briquette Testing Machine (Right)

The tensile strength of mortar at 28 days is reduced by $5.01 \%$ for PPF at $1 \%, 18.67 \%$ for PPF at $2 \%$ and $31.24 \%$ for PPF at 3\% (Refer Figure 11).

FLEXURAL STRENGTH: The flexural strength of hydraulic cement mortar in pounds/inches 2 is determined by testing prisms of size (6" $\left.\times 1.5^{\prime \prime} \times 1.5^{\prime \prime}\right)$ by third point load test (See Figure 12). Forty-eight wooden moulds were prepared for making 48 samples to be tested. The interior faces of the moulds were first lubricated with oil and the excess oil was then wiped off with the help of the cloth. The halves of the moulds were sealed with grease. Then the first layer of mortar was poured in 2-inch thickness in the mould and tamped 20 times with the tamper. The tamping was done uniformly. The same procedure was repeated for second layer. After the top layer was tamped, the mortar was cut off to a plane surface and flushed it with the top of the mould with the help of a straightedge. In this way all the forty-eight moulds were filled with specified mixes. The moulds were kept in a moist room for 24 hours. The mortar beams were then taken out of the moulds by loosening the screws fixed in the wooden moulds. The mortar beams were then kept in water filled pan in such a way that their top faces do not drip into water. The harden samples were then tested in Universal Testing Machine by third point loading and the load at rupture was noted for further calculations. The flexural strength of the mortar beams was determined by third point load test in UTM.

The flexural strength of the PPFMM beams (28 days) also reduced by $32.29 \%$ at PPF $1 \%, 47.92 \%$ at PPF $2 \%$ and $66.07 \%$ at PPF $3 \%$ (Refer Figure 13 ).

PERMEABILITY: The permeability of the hydraulic cement mortar as shown in Figure 14 was determined by testing cylinders (3-7/8" dia x 6" depth) in inches/second. Twelve plastic moulds were prepared for making 12 samples to be tested. The interior faces of the moulds were first lubricated with oil and the excess oil was then wiped off with the help of the cloth. The halves of the moulds were sealed with grease. Then the first layer of mortar was poured in 2-inch thickness in the mould and tamped 20 times with the tamper. The tamping was done 
uniformly. The same procedure was repeated for second layer. After the top layer was tamped, the mortar was cut off to a plane surface and flushed it with the top of the mould with the help of a straightedge. In this way all the twelve moulds were filled with specified mixes. The moulds were kept in a moist room for 24 hours. The cylinders were then taken out of the moulds by loosening the screws fixed in the moulds. The cylinders were then kept in water filled pan in such a way that their top faces do not drip into water. After 28 days, the hardened samples were tested in permeability apparatus which is specifically designed for concrete but can also be used for mortar. The samples were first oven dried hardened at $105^{\circ} \mathrm{C}$.
The samples were then cleaned with the help of wire brush and coated with oil-based paint over the circumference so that water could permeate through its top and bottom surfaces only. The paint was left to dry sufficiently 24 hours, then the sample was put in the assembly and sealed tightly with epoxy resin. The assembly was then fixed with the help of nuts and bolts tightly in such a way to make it air tight. The epoxy resin was allowed to dry for another 24 hours. A hydrostatic pressure of $0.5 \mathrm{MPa}$ was applied to the specimen. The time and amount of water passed through the specimen was monitored until a steady flow rate was obtained. In this way all the samples were tested for permeability.

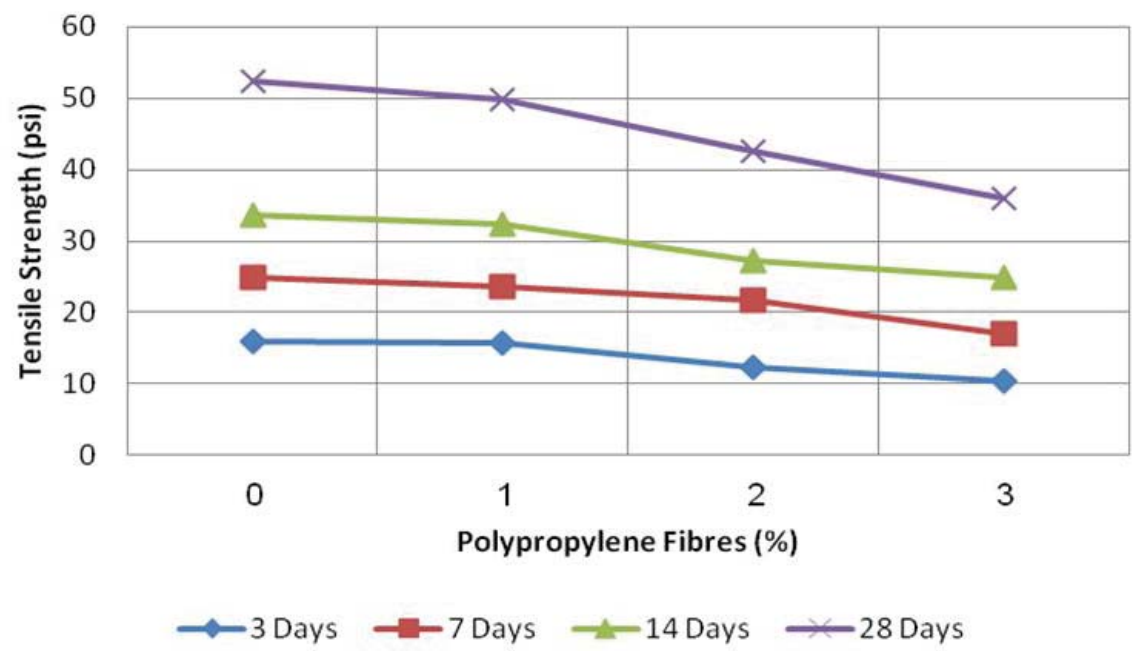

Figure 11: Graph showing decrease in tensile strength with increasing PPF
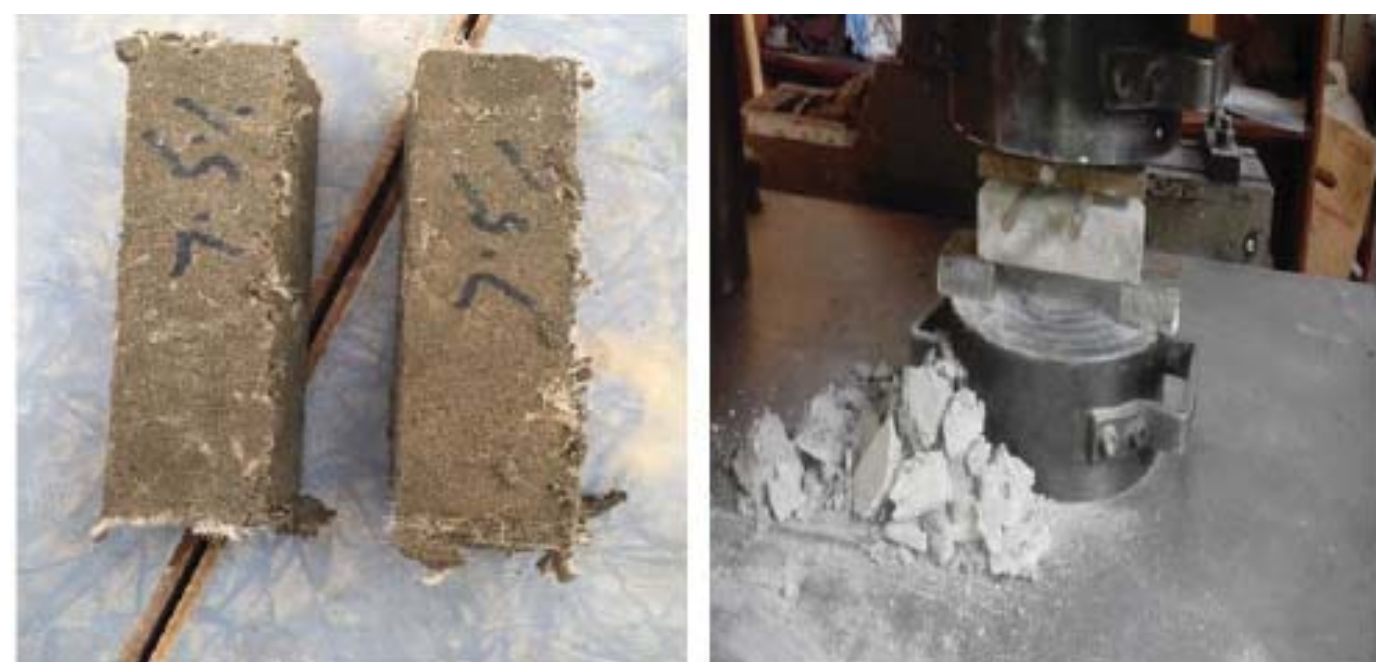

Figure 12: Beam Samples \& Universal Testing Machine

As clear from Figure 15 the permeability coefficient increased with increase in the PPF fraction i.e. for PPF at
$1 \%$ it increased by $60 \%$, for PPF at $2 \%$ it increased by $140 \%$ and for PPF at $3 \%$ it increased by $194 \%$. 


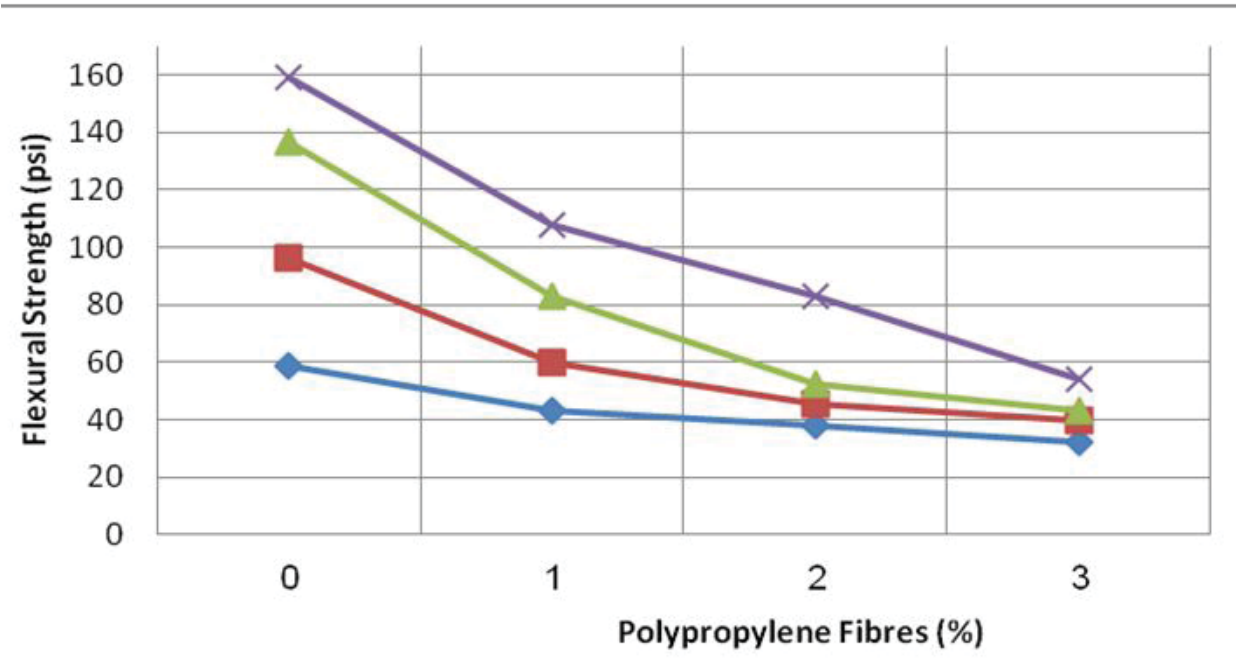

$\multimap 3$ Days $\rightarrow-7$ Days $\longleftarrow 14$ Days $\longleftarrow 28$ Days

Figure 13: Graph showing decrease in flexural strength with increasing PPF
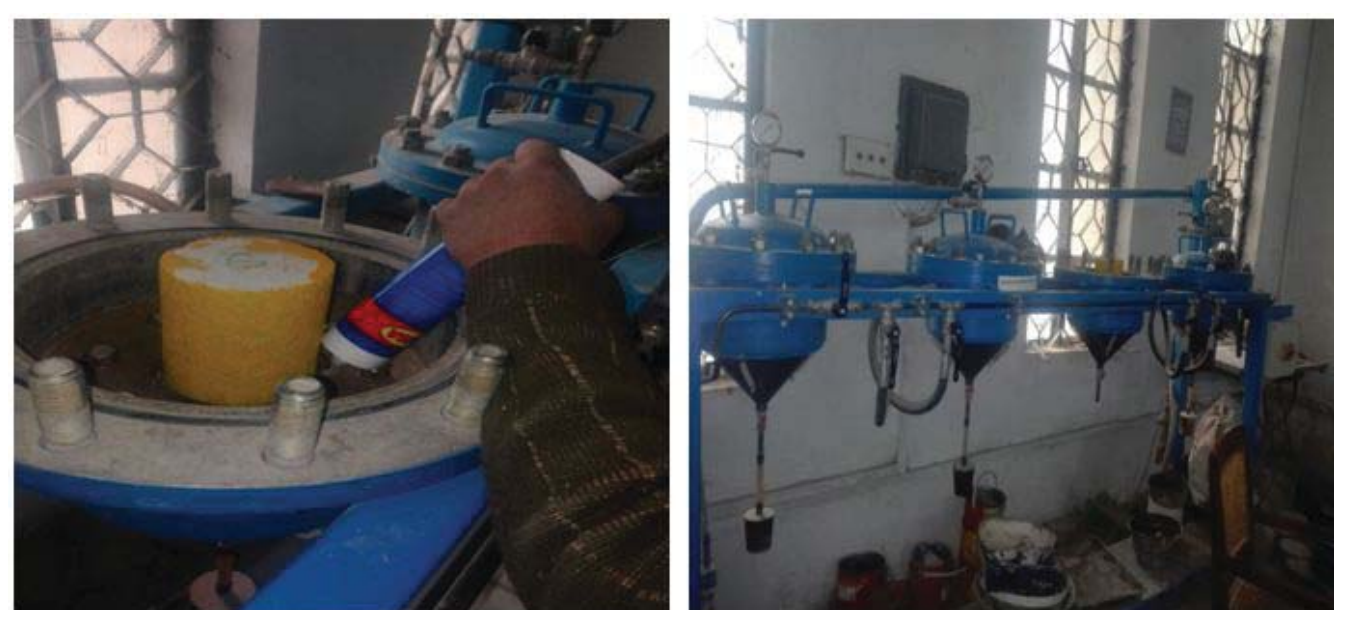

Figure 14: Cylinder Samples (Left) \&Permeability Apparatus (Right)

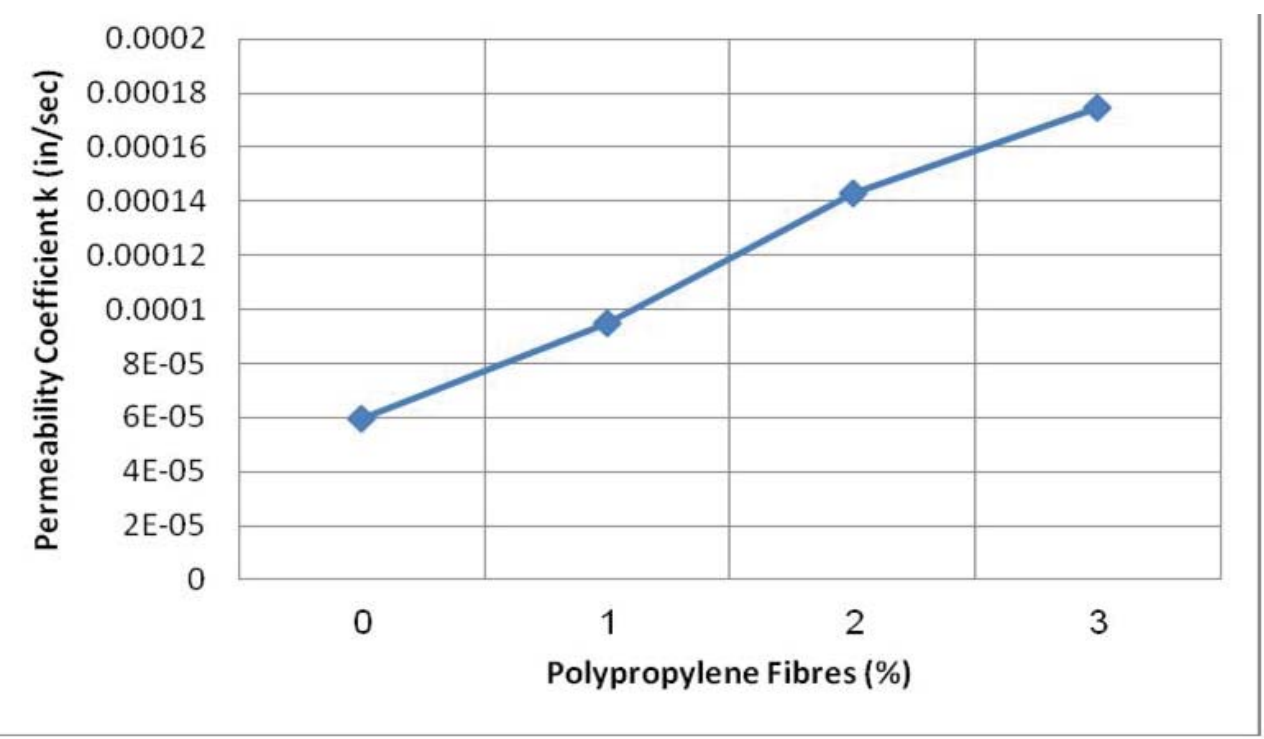

Figure 15: Graph showing increase in permeability coefficient with increasing PPF 


\section{CONCLUSION}

The following conclusions were observed from this experimental activity:

- As the porosity of the polypropylene fibers mixed mortar increases with increasing fraction of polypropylene fibers, therefore, its use in water retaining structures is not recommended.

- While observing tests on compression testing machine and briquette testing machine, it was concluded that the control samples were crushed into small pieces while those containing fibers didn't crush into small pieces.

- The test results obtained for mechanical properties for PPFM cement-sand mortar shows that its use in cement-sand mortar cannot be recommended at these fractions as the strength is reduced by manifolds, however, its use by less than $1 \%$ in mortar mix is recommended as its effect on strength will be negligible and the ductility of the mortar will also increase considerably.

- In the end it is believed that this work can be extended further to calculate an optimum level of polypropylene fibers in mortar.

\section{REFERENCES}

1. C. D. Johnston, Fiber-reinforced cements and concretes: Crc Press, 2014.

2. O. Karahan and C. D. Atiş, "The durability properties of polypropylene fiber reinforced fly ash concrete," Materials \& Design, vol. 32, pp. 1044-1049, 2011.

3. S. Ahmed, et al., "A study on properties of polypropylene fiber reinforced concrete," in 31st Conference on Our World in Concrete and Structures, pp. 63-72, 2006.

4. G. S. Islam and S. D. Gupta, "Evaluating plastic shrinkage and permeability of polypropylene fiber reinforced concrete," International Journal of Sustainable Built Environment, vol. 5, pp. 345-354, 2016.

5. Alhozaimy, A. M., Soroushian, P., \& Mirza, F. Mechanical properties of polypropylene fiber reinforced concrete and the effects of pozzolanic materials. Cement and Concrete Composites, 18(2), 85-92, 1996.

6. Fanella, D. A., \& Naaman, A. E. Stress-strain properties of fiber reinforced mortar in compression. Journal of The American Concrete Institute, 82(4), 475-483, 1985.

7. Li Bei-Xing; Cheng Ming-Xian; Cheng Fang and Liu Lu-Ping; The mechanical properties of polypropylene reinforced concrete; Wuhan University of Technology, China, 2004.

8. KolliRamuji\& VNR Vignana Jyoti; Strength properties of polypropylene fibers reinforced concrete; Institute of Engineering and Technology, Hyderabad, India, 2013.

9. Aulia, T. B. Effects of polypropylene fibers on the properties of high-strength concretes. Institutes for Massivbau and Baustoffechnologi, University Leipzig, Lacer, 2002.

10. Deng, Z., and Li, J., Tension and Impact Behaviours of New Type Fiber Reinforced Concrete,Computers and Concrete, Concrete. Vol. 4, No.1, pp.19-32, 2007.

11. Ramlal, C. A., \&Selokar. G. R. Synthesis And Characterization Of Polypropylene Fiber Reinforced Concrete, 1994.

12. Shehnila Fatima; Mechanical Properties of Polypropylene Fiber Reinforced Concrete and Structural Applications; NED University of Engineering and Technology, Karachi, 2013.

13. Erdogmus, E. Use of fiber-reinforced cements in masonry construction and structural rehabilitation. Fibers, 3(1), 41-63, 2015.

14. [ASTM Standard C-150, "Type I or II, except Type III may be used for cold-weather construction," in Provide natural color or white cement as required to produce mortar color indicated vol. 1, ed. West Conshohocken, PA, USA, 1993.

15. ASTM Standard C 33, "Aggregates, B Normal-WeightClass $3 S$ coarse aggregate or better, graded," in Provide aggregates from a single source vol. 1, ed, pp. 1-1, 2003.

16. ASTM Standard C1437-15, "Standard test method for flow of hydraulic cement mortar," in C 1437, ed. West Conshohocken, PA, USA, 2007.

17. ASTM Standard C-231/231M-14, "Standard test method for air content of freshly mixed concrete by the pressure method," ed. West Conshohocken, PA, USA, 2010.

18. ASTM Standard C807-13, "Standard test methods for time of setting of hydraulic cement by Vicat needle," ed. West Conshohocken, PA, USA., 2008.

19. ASTM Standard C109/C109M-16a, "Standard Test Method for Compressive Strength of Hydraulic Cement Mortars (using 2-in. Or [50-mm] Cube Specimens)," in Committee C-1 on Cement, ed. West Conshohocken, PA, USA: ASTM International, 2013.

20. ASTM Standard C307-03, "Standard Test Method for Tensile Strength of Chemical-Resistant Mortar, Grouts and Monolithic Surfacing;", in Committee C-1 on Cement, ed. West Conshohocken, PA, USA: ASTM International, 2012.

21. ASTM Standard C1609/C1609M-07, "Standard test method for flexural performance of fiber-reinforced concrete (using beam with third-point loading). West Conshohocken (PA): ASTM International," ed: ASTM 2010.

22. German Standard DIN 12390, "Standard Test Method for Permeability Coefficient of Hydraulic Cement Mortar; " ed. Germany, 2009.

Paper submitted: 07.10.2018.

Paper accepted: 10.03.2019.

This is an open access article distributed under the CC BY-NC-ND 4.0 terms and conditions. 